\title{
A Report of Two Deaths from Massive Ibuprofen Ingestion
}

\author{
William Holubek, MD ${ }^{a}$, Andrew Stolbach, MDa , Saul Nurok, MD, MS , Olivia Lopez, MD ${ }^{b}$, \\ Alyson Wetter, $\mathrm{MD}^{c}$, Lewis Nelson, $\mathrm{MD}^{a}$
}

aNYCPCC

bNew York Methodist Hospital, Department of Emergency Medicine

cWestchester Medical Center, New York

\section{ABSTRACT}

Introduction: Ibuprofen is a commonly used non-steroidal anti-inflammatory drug. While the vast majority of exposures to the drug do not result in significant morbidity, we are reporting 2 fatalities that resulted from massive ibuprofen ingestion.

Case 1: A 17-year-old girl presented to the emergency department (ED) following an ibuprofen overdose; she was unresponsive with a metabolic acidosis and hypothermic. Her serum ibuprofen concentration was $352 \mu \mathrm{g} / \mathrm{mL}$ : the therapeutic range is $10-50 \mu \mathrm{g} / \mathrm{mL}$. Despite intensive supportive care and continuous veno-venous hemofiltration, she expired.

Case 2: A 49-year-old man presents to the ED with a history of divalproex sodium and ibuprofen ingestion. He was unresponsive, hypotensive, and had a significant metabolic acidosis. His serum ibuprofen concentration was $260 \mu \mathrm{g} / \mathrm{mL}$ and serum valproate concentration was $560 \mu \mathrm{g} / \mathrm{mL}$ : the therapeutic range is $50-100 \mu \mathrm{g} / \mathrm{mL}$. In spite of supportive care and hemodialysis, he expired.

Discussion: We will describe 2 cases of ibuprofen overdose characterized by cardiovascular collapse, acidosis, and hypothermia despite the use of vasopressors and renal replacement therapy. Although rarely reported, massive ibuprofen overdose may result in refractory multisystem organ failure and death.

\section{INTRODUCTION}

Ibuprofen, one of the propionic acid class drugs, is a widely used non-steroidal anti-inflammatory drug (NSAID). In 2005, the American Association of Poison Control Centers received reports of 71,109 exposures and 25 deaths associated with ibuprofen use [1]. The majority of these reported deaths involved coingestants, and ibuprofen was unlikely to be the primary, causative factor. The vast majority of reports did not confirm ibuprofen concentrations. There are many reports in the medical literature of acute, intentional ingestions; however, most of these reports suffer from similar limitations [2]. We will present two cases of fatal ibuprofen overdose with documented serum concentrations.

Case 1: A 17-year-old girl with a history of suicide attempts was found in her bedroom by her family. She was described as "unresponsive," and she was surrounded by orange-colored vomitus. Next to her was a large bottle of ibuprofen: only 1 pill remained. Although the original number of pills in the bottle is unclear, the label advertised 1,000 tablets of $200 \mathrm{mg}$ ibuprofen each.

She was last seen approximately 13 hours prior to discovery. Her medications included sertraline (150 mg QD) and inhaled albuterol. Her pre-hospital fingerstick glucose was $2 \mathrm{mg} / \mathrm{dL}(0.11$ $\mathrm{mmol} / \mathrm{L}$ ). She was intravenously (IV) given 25 grams of dextrose. She did not respond and was then intubated by the paramedics. In the ED her initial vital signs were as follows; systolic blood pressure, $70 \mathrm{mmHg}$; pulse, 70/minute; and rectal temperature, $91^{\circ} \mathrm{F}$. Her fingerstick glucose was $120 \mathrm{mg} / \mathrm{dL}(2.60 \mathrm{mmol} / \mathrm{L})$, and her physical exam was unremarkable. The initial return of an orogastric lavage showed an orange, grainy material that eventually cleared after the administration of 6 liters of fluid. An unspecified dose of activated charcoal was administered. Arterial blood gas showed a $\mathrm{pH}, 7.08$; $\mathrm{pCO}_{2}, 30 \mathrm{mmHg} ; \mathrm{pO}_{2}, 357 \mathrm{mmHg}$; bicarbonate, $8 \mathrm{mmol} / \mathrm{L}$; and a

Keywords: ibuprofen, overdose, poisoning, acidosis, valproate

Notes: There was no outside funding of any kind used for this study.

Corresponding Author: Andrew Stolbach. Email: andrewstolbach@hotmail.com 
lactate of $17 \mathrm{mmol} / \mathrm{L}$. The initial, clinical laboratory studies showed a serum bicarbonate of $13 \mathrm{mmol} / \mathrm{L}$; an anion gap of $32 \mathrm{mmol} / \mathrm{L}$; a creatinine of $1.5 \mathrm{mg} / \mathrm{dL}$ (132.6 mmol/L); an AST of $108 \mathrm{U} / \mathrm{L}$; an ALT of $83 \mathrm{U} / \mathrm{L}$, and a normal coagulation profile. Serum acetaminophen and aspirin concentrations were undetectable. A urine drug screen on admission was positive only for cocaine and cannabinoids. Electrocardiogram (ECG) was significant only for a prolonged QTc interval of $506 \mathrm{msec}$. She was empirically started on gatifloxacin and clindamycin and then given a stress dose of steroids.

In the intensive care unit, she required epinephrine, norepinephrine, dopamine, and vasopressin to maintain adequate blood pressure. Over the first 12 hours of admission, aggressive management with intravenous saline and sodium bicarbonate was administered in an attempt to reduce her acidosis. However, $\mathrm{pH}$ remained at 7.14; serum bicarbonate at $10 \mathrm{mmol} / \mathrm{L}$; lactate at $30 \mathrm{mmol} / \mathrm{L}$; anion gap at 48; and sodium increased to $161 \mathrm{mmol} / \mathrm{L}$. On day 1 , continuous veno-venous hemofiltration $(\mathrm{CVVH})$ was instituted. She also developed A-V dissociation with a wide complex (rate $100 \mathrm{bpm}$, QRS $203 \mathrm{msec}$, and QTc $447 \mathrm{msec}$ ) that spontaneously resolved. She remained unresponsive. On hospital day 2, a head CT showed diffuse edema and small ventricles. Her serum ibuprofen concentration at this time was $352 \mu \mathrm{g} / \mathrm{mL}$ : the therapeutic range is $10-50 \mu \mathrm{g} / \mathrm{mL}$. Despite aggressive supportive care with multiple blood products, she developed disseminated intravascular coagulation and multiorgan system failure. On hospital day 9, the parents signed a DNR (do not resuscitate) order, and the patient died later that day.

Case 2: A 49-year-old man with a medical history of bipolar disorder and hypothyroidism was discovered by his ex-girlfriend; he was comatose with shallow respirations and there was a pool of fresh vomitus. Next to him were 2 empty bottles of ibuprofen. The label advertised 600 tablets of $200 \mathrm{mg}$ ibuprofen each. In addition, there was an empty bottle of divalproex sodium (Depakote). The patient had no prior suicide attempts, but he was noted to be increasingly manic after a recent change in his divalproex sodium regimen. His only other chronic medication was levothyroxine. The patient was given dextrose 25 grams IV, thiamine $100 \mathrm{mg} \mathrm{IV}$, and naloxone $1 \mathrm{mg}$ IV in the field. There was no response. In the ED, his initial vital signs were as follows: blood pressure, 60/45 $\mathrm{mmHg}$; pulse, 115/min; and rectal temperature, $89.3^{\circ} \mathrm{F}$. The patient was obtunded, and his pupils were $4 \mathrm{~mm}$ bilaterally and sluggishly reactive to light. He had a distended abdomen with diminished bowel sounds; the stool was negative for occult blood. The patient was intubated in the ED and was intravenously given 2 liters of normal saline over 1 hour. While on a $100 \%$ nonrebreather mask, arterial blood gas showed a pH of 6.71 ; a $\mathrm{pCO}_{2}$ of $48.5 \mathrm{mmHg}$; a $\mathrm{pO}_{2}$ of $161 \mathrm{mmHg}$; and a bicarbonate of $6.2 \mathrm{mmol} / \mathrm{L}$. His initial clinical laboratory studies showed the following: a WBC of $39.7 \times 10^{3} / \mu \mathrm{L}$; a serum bicarbonate of $5 \mathrm{mmol} / \mathrm{L}$; an anion gap of $45 \mathrm{mmol} / \mathrm{L}$; a potassium of $5.7 \mathrm{mmol} / \mathrm{L}$; a BUN of $41 \mathrm{mg} / \mathrm{dL}(14.63 \mathrm{mmol} / \mathrm{L})$; a creatinine of $3.8 \mathrm{mg} / \mathrm{dL}$ (335.9 mmol/L); and an ammonia of $639 \mu \mathrm{g} / \mathrm{dL}$ (375 $\mu \mathrm{mol} / \mathrm{L}$ : the normal range is $10-80 \mu \mathrm{g} / \mathrm{dL}$ or $5.8-47 \mu \mathrm{mol} / \mathrm{L}$ ). Aminotransferases and coagulation studies were unremarkable.
Serum acetaminophen and salicylate concentrations were undetectable. A urine drug screen was negative. The serum valproate concentration was reported as $560 \mu \mathrm{g} / \mathrm{mL}$, for which he received $15 \mathrm{mg} / \mathrm{kg}$ intravenous levocarnitine for 30 minutes every 4 hours. (The therapeutic range for serum valproate is $50-150 \mu \mathrm{g} / \mathrm{mL}$ ).

An electrocardiogram showed sinus bradycardia at 53/min. The QTc was prolonged at $563 \mathrm{msec}$. While in the ED, the patient received $244.6 \mathrm{mEq}$ boluses of intravenous sodium bicarbonate, nasogastric lavage with an 18 French tube with subsequent activated charcoal administration, warming blanket, 3 liters of warmed normal saline, and broad-spectrum antibiotics. To maintain blood pressure, norepinephrine was infused at $10 \mu \mathrm{g} / \mathrm{min}$. A chest $\mathrm{x}$-ray indicated diffuse air space opacification in the superior segment of the right lower lobe, and a nephrologist determined that the patient was too unstable for hemodialysis.

On hospital day 2 , the patient developed a fever, and a chest radiograph revealed bilateral symmetrical infiltrates. Blood drawn from hospital day 1 showed a serum ibuprofen concentration of $260 \mu \mathrm{g} / \mathrm{mL}$, a valproate concentration of $250 \mu \mathrm{g} / \mathrm{mL}$, an ammonia of $210 \mu \mathrm{g} / \mathrm{dL}(123 \mu \mathrm{mol} / \mathrm{L})$, and an elevated aminotransferases with AST at $412 \mathrm{U} / \mathrm{L}$ and ALT at $165 \mathrm{U} / \mathrm{L}$. Despite pressors, intravenous sodium bicarbonate and, ultimately, hemodialysis-he expired the following morning.

\section{DISCUSSION}

Ibuprofen, 2-(4-isobutylphenyl) propionic acid, is a nonsteroidal drug with anti-inflammatory, antipyretic, and analgesic properties. It was introduced to the United States in 1974 as a prescription drug, and it has been nonprescription since 1984 [3]. The number of reported ibuprofen overdoses has increased since the nonprescriptive availability of the drug. However, most of the literature concerning ibuprofen focuses on toxicity arising from its chronic use, such as gastrointestinal bleeding and analgesic nephropathy $[4,5]$. As described in the literature, acute ibuprofen overdose is the result of a wide range of clinical effects, most of which are minor in severity.

Although the vast majority of reported ibuprofen overdoses are not consequential, characteristics of acute massive ibuprofen overdoses include coma, seizures, metabolic acidosis, gastrointestinal bleeding, shock, acute renal failure, hepatotoxicity, cholestasis, thrombocytopenia, and death [6].

There are few reports of ibuprofen death in the literature. One series summarized 7 of the 9 cases reported in the literature as ibuprofen deaths [2]. Of the seven cases, four had toxic coingestants, one patient died of sepsis, one patient refused hemodialysis, and the other case was a postmortem diagnosis of ibuprofen toxicity with an unknown manner of death [7]. Recently, 2 case reports describing ibuprofen related deaths were published. The first case describes a 26-year-old woman who presented to a health care facility within 5 hours of ingesting 105 grams of sustained-release ibuprofen [14]. When she presented, she had a decreased level of consciousness, hypotension, severe metabolic acidosis, and an elevated serum lactate. Her serum 
ibuprofen concentration was $760 \mathrm{mg} / \mathrm{mL}$, and a serum toxicology screen revealed no co-ingestants. Her condition was refractory to hemofiltration and maximum doses of vasopressors. After 5 hours in the ED, she died from a ventricular tachycardia/ventricular fibrillation arrest. The second case describes a 33-year-old woman who died on hospital day 4 from circulatory failure after she reportedly ingested 36 grams of ibuprofen. Although the death is attributed to ibuprofen, the case does not document any confirmatory concentration [15].

A serum ibuprofen concentration confirms ibuprofen ingestion by a patient; however, these levels do not correlate well with clinical toxicity or outcome. For example, a 16-year-old boy had a serum ibuprofen concentration of $160 \mu \mathrm{g} / \mathrm{mL} 7$ hours postingestion, and he presented with unresponsiveness, hypothermia, and metabolic acidosis [19]. In contrast, a group of 22 ibuprofenoverdose patients who had serum ibuprofen levels ranging from 4 to $750 \mu \mathrm{g} / \mathrm{mL}$ did not develop any severe or life-threatening toxicity [18]. In an attempt to correlate serum level with toxicity, an ibuprofen nomogram was constructed, but its utility is extremely limited and its use not recommended [17]. Many factors can explain this lack of utility of serum ibuprofen levels to predict toxicity; they include co-morbidities, co-ingestants, and the time post-ingestion when the sample was obtained. Thus, a serum concentration associated with severe toxicity in 1 case report may be tolerated very well in another.

Predicting the severity of symptoms in adults, based on the reported ingested amount, remains very difficult. A good analysis should use a weight-adjusted dose, but most case reports do not include the patient's weight-making it impossible to verify the accuracy of reported doses. The lowest reported ibuprofen ingestion that produced CNS depression was 3 grams, but neither the age of the patient nor a serum ibuprofen concentration were reported [18]. Pediatric data suggests that ingestions reported as less than $100 \mathrm{mg} / \mathrm{kg}$ result in little or no symptoms, while ingestions reported as greater than $400 \mathrm{mg} / \mathrm{kg}$ are associated with the development of symptoms [17]. In the adult literature (defined in these studies as patients $>14$ years of age), cases of reported ingestions ranged from 1.2 grams to 105 grams. The only death attributed solely to ibuprofen in the current literature, with a documented serum concentration and unresponsiveness to aggressive care, was a 105 gram ingestion of sustained release ibuprofen [14]. This suggests that ingestions greater than 100 grams may be associated with a higher risk of mortality. However, conclusions from this type of analysis should be used with caution, as the initial data likely include patients who actually ingested less than reported, thus making the ingestion appear less dangerous.

The patient described in Case 1 reportedly ingested nearly 200 grams of ibuprofen, while the patient in Case 2 may have ingested up to 120 grams of ibuprofen. Even using conservative estimates of their weight, these ingestions are much greater than $400 \mathrm{mg} / \mathrm{kg}$, and this is consistent with severe toxicity. Both of the patients we described presented in a manner similar to previouslyreported ibuprofen fatalities; they reported CNS depression, metabolic acidosis, renal insufficiency, prolonged QTc, hypothermia, and thrombocytopenia. Despite receiving extremely aggressive care, neither survived. The two major difficulties early in their management (severe acidosis refractory to intravenous saline and sodium bicarbonate therapy and profound hypotension) required multiple vasopressor agents.

Each patient described in this series had a very high anion gap on presentation (32 and $45 \mathrm{mmol} / \mathrm{L}$.) While the lactate concentration for the patient in Case 2 is not available, the patient in Case 1 had an elevated serum lactate concentration. (In addition to the contribution of lactic acidosis from profound hypoperfusion that is often reported in patients with massive overdose, the speculated cause of metabolic acidosis is the large amounts of ibuprofen and its weak acid metabolites (2-carboxyibuprofen and 2-hydroxyibuprofen) $[8,9,14]$.

Both patients developed hyperkalemia, probably from metabolic acidosis and renal insufficiency. Interestingly, the patient in Case 1 developed sudden hyperkalemia with ECG changes despite CVVH. Hyperkalemia associated with acute ibuprofen overdose has been previously reported, but an iatrogenic administration of potassium chloride complicated the case [10].

Renal replacement therapy was instituted in each case (hemodialysis or CVVH). Although potentially beneficial for correcting a metabolic acidosis, studies show hemodialysis is ineffective for increasing clearance of ibuprofen despite its low volume of distribution $(0.15 \mathrm{~L} / \mathrm{kg})$, probably because the drug is nearly completely protein bound in the plasma $[11,12,13]$.

Coingestants often play a significant role in ibuprofen overdoses. A serum toxicological screen and history of the patient in Case 1 did not reveal any significant coingestants. Her urine drug screen was positive for cocaine and tetrahydrocannabinoids: this is consistent with her history of cocaine use, without adverse effect, at a party the night before presentation. At the time her care was withdrawn, her blood pressure was maintained with pressors, and she had no measurable neurological function. A clinical outcome of death was almost certain, and it can be completely attributed to ibuprofen.

Unlike the patient in Case 1, the patient in Case 2 took a significant coingestant. Although the presence of hyperammonemia suggests that the patient was experiencing valproate toxicity, we feel that ibuprofen was the principal cause of death for several reasons:

(1) serum valproate levels were significantly lower than those usually associated with death in other series; our patient's peak valproate concentration was $560 \mu \mathrm{g} / \mathrm{mL}$, while reported fatalities had concentrations $>1000$ $\mu \mathrm{g} / \mathrm{mL}$;

(2) the patient's clinical deterioration continued despite an improvement in serum ammonia and institution of hemodialysis;

(3) serum ibuprofen concentration was elevated confirming an ibuprofen ingestion; and

(4) the patient's profound refractory acidosis, hypothermia, and renal insufficiency are consistent with ibuprofen poisoning [21-25]. 
We described 2 cases of ibuprofen overdose characterized by cardiovascular collapse, acidosis, and hypothermia despite vasopressors and renal replacement therapy. Although rarely reported, massive ibuprofen overdose may result in refractory multisystem organ failure and death.

The authors have no potential financial conflicts of interest to report.

\section{REFERENCES}

1. Lai M, Klein-Schwartz W, Rodgers GC, Abrams JY, Haber DA, Bronstein AC, Wruk KM. The 2005 annual report of the American Association of Poison Control Centers' national poisoning and exposure database. Clin Toxicol. 2006; 44 : 803-932.

2. Volans G, Monaghan J, Colbridge M. Ibuprofen overdose. Int J Clin Pract Suppl. 2003;135:54-60.

3. McElwee NE, Veltri JC, Bradford DC, Rollins DE. A prospective, population-based study of acute ibuprofen overdose: Complications are rare and routine serum levels not warranted. Ann Emerg Med. 1990;19:657-662.

4. Lewis JD, Kimmel SE, Localio AR, Metz DC, Nessel JT, Brensinger L, et al. Risk of serious upper gastrointestinal toxicity with over-the-counter nonaspirin nonsteroidal antiinflammatory drugs. Gastroenterology. 2005;129:1865-74.

5. Henry D, McGettigan P, Epidemiology overview of gastrointestinal and renal toxicity of NSAIDs. Int J Clin Pract Suppl. 2003; 135 :43-49.

6. Seifert SA, Bronstein AC, McGuire T. Massive ibuprofen ingestion with survival. Clin Tox. 2000;38:55-57.

7. Kunsman GW, Rohrig TP. Tissue Distribution of ibuprofen in a fatal overdose. Am J Forensic Med Pathol. 1993;14:48-50.

8. Linden $\mathrm{CH}$, Townsend PL. Metabolic acidosis after acute ibuprofen overdosage. J Pediatr. 1987;111:922-925

9. Downie A, Ali A, Bell D. Severe metabolic acidosis complicating massive ibuprofen overdose. Postgrad Med J.

1993; 69:575-577.

10. Menzies DG, Conn AG, Williamson IJ, Prescott LF. Fulminant hyperkalaemia and multiple complications following ibuprofen overdose. Med Toxicol Adverse Drug Exp.

1989;4:468-471.
11. Senekjian HO, Lee CS, Juo TH, Au DS, Krothapalli R. Absorption and disposition of ibuprofen in hemodialyzed uremic patients. Eur J Rheumatol Inflamm 1983;6:155-162.

12. Paliwal JK, Smith DE, Cox SR, Berardi RR, Dunn-Kucharski VA, Elta GH. Stereoselective, competitive, and nonlinear plasma protein binding of ibuprofen enantiomers as determined in vivo in healthy subjects. J Pharmacokinet

Pharmacodyn. 1993;21:145-161.

13. Brunton LL , editor. Goodman and Gilman's the Pharmacological Basis of Therapeutics (11 th $\mathrm{ed}$.). New York: McGraw Hill; 2006. p.1834.

14. Wood DM, Monaghan J, Streete P, Jones AL, Dargan PI. Fatality after deliberate ingestion of sustained-release ibuprofen: a case report. Critical Care. 2006;10:R44.

15. Krenova M, Pelcova D. Fatal poisoning with ibuprofen. Clin Toxicol. 2005; $43: 537$.

16. Le HT, Bosse GM, Tsai Y. Ibuprofen overdose complicated by renal failure, adult respiratory distress syndrome, and metabolic acidosis. Clin Toxicol. 1994;32(3):315-320.

17. Hall AH, Smolinske SC, Conrad FL, Wruk KM, Kulig KW, Dwelle TL, et al. Ibuprofen overdose: 126 cases. Ann Emerg Med. 1986; $15: 1308-1313$.

18. Hall AH, Smolinske SC, Stover B, Conrad FL, Rumack BH. Ibuprofen overdose in adults. Clin Toxicol. 1992;30(1):23-37.

19. Ritter A, Eskin B. Ibuprofen overdose presenting with severe agitation and hypothermia. Am J Emerg Med.

1998; 16(5):549-550.

20. Wolfe TR. Ibuprofen overdose. Am J Emerg Med. 1995; $13(3): 375$.

21. Poklis A et al. Disposition of valproic acid in a case of fatal intoxication. J Anal Toxicol. 1998;22:537-540.

22. Lee WL, Yang CC, Deng JF et al. A case of severe hyperammonemia and unconsciousness following sodium valproate intoxication. Vet Hum Toxicol. 1998;40:346-348.

23. Andersen GO, Ritland S. Life threatening intoxication with sodium valproate. J Toxicol Clin Toxicol. 1995;33:279-284.

24. Connacher AA, McNab MS, Moody JP, Jung RT. Fatality due to massive overdose of sodium valproate. Scott Med J. 1987;32:85-86.

25. Spiller HA, Krenzelok EP, Klein-Schwartz W, et al. Multicenter case series of valproic acid ingestion: Serum concentrations and toxicity. J Toxicol Clin Toxicol. 2000;38:755-760. 